\title{
A FUZZY APPROACH TO EVALUATE SUITABILITY OF INFRASTRUCTURE PROJECTS WITH SAFETY
}

\author{
Gaurav Ramesh Pawar ${ }^{1}$, Purushottam Dange ${ }^{2}$, R. K. Lad ${ }^{3}$ \\ ${ }^{1}$ PG Student, Construction and Management Department of Civil Engineering, Dr. D. Y. Patil Institute of Engineering \\ and Technology Pimpri Pune-18, Maharashtra, India \\ ${ }^{2}$ Professor, Department of Civil Engineering, Dr. D. Y. Patil Institute of Engineering and Technology Pimpri Pune-18 \\ , Maharashtra, India \\ ${ }^{3}$ Dean Administration,Department of Civil Engineering, Dr. D. Y. Patil Institute of Engineering and Technology \\ Pimpri Pune-18, Maharashtra, India
}

\begin{abstract}
The current project deals with safety management in highways and infrastructure (Buildings and Roads).The research is partly doctrinal and partly empirical in natural. Research tools used is fuzzy logic. The scope research has been to mainly cover highways and infrastructure (Buildings and Roads).The topic of construction includes the process of Highways, Building and society roads, construction and maintenance, including the design of respective construction, contracting, accomplishing, supervision, and maintenance of Highways, Building, society roads and related structures. Our study of project will fulfil the safety requirements by using Fuzzy logic that should be consider before starting highways and infrastructure (Buildings and Roads) and this study will be very helpful in construction industry. as this study will decrease the chances of accidents as well as to save lives. Today so many people lose their lives when traffic has to move through maintenance works and road construction every year also during the construction of Buildings. The cases of construction section injuries and accidental death are predicted to go even higher than now. Construction in highways and infrastructure (Building and Roads) covers various activities, techniques, materials and source of danger therefore because of this conditions the probability of accidents increases every time. The fact is construction industry has the most disappointing record of safety compare to all industrial sectors, with a risk of casualty 5 times higher than several other industry in the world. The higher rate of accidents and deaths in the construction industry compare to all other industries are may be due to the process of the construction work. The factors due to which the rate of accidents are high in construction industry are such as poor planning, lack of safety training, lack of supervision, lack of safety equipment, and lack of incident investigation helps to create more problems in future. Hence, by using Multi criteria decision making by Fuzzy logic will reduce the risk of accidents while construction of highways and infrastructure (Building and Roads).
\end{abstract}

Keywords: Highway and Infrastructure Safety, Defuzzification, Fuzzy Multi Criteria Decision Making, Expert Opinion, Linguistic Terms and Safety Potential Index

\section{INTRODUCTION}

Now days in India or we can say everywhere safety regarding every aspect that could be in chemical, manufacturing, glass, etc. industries are very important as it involves skilled or unskilled labour lives and this source is significantly important and this source cannot be replaced by any other resource. In construction industry the safety issues are very important, as in construction industry heavy equipment(s), falling objects, excavations, etc. are involved and this kind of risks can take lives. So the safety in construction industry has to be in higher level of priorities.

Our study of the project will fulfil the safety requirements that should be considered for highways and infrastructure (Buildings and Roads) this study will be very helpful in construction industry as this study will decrease the chances of accidents as well as to save lives.

Safety can be said to be a feeling of welfare and security insured by the activity a person indulges in. Safety is the condition of being secure. During construction projects as has been seen many risk factors are involved. To protect a person from such risks a proper program of safety and security should be formulated.

Due to increasing the infrastructure budget and funding for Highways and road construction are resulting huge increase in the number of highway and road construction projects in India. Also, the safety of road consumers and people who are working is important concern on roads and highways worldwide.

Today so many people lose their lives when traffic has to move through road construction and maintenance works every year, also during the construction of Buildings. The cases of construction section injuries and accidental death are predicted to go even higher than now

Zongzhi Li, Konstantinos Kepaptsoglou, Yongdoo Lee, Harshingar Patel, Yi Liu, and HanGyol Kim [15], have 
introduced ananalysis method toassess the effects of highway projects on safety performance.

C. E. Jackson [3] suggested that, from the year 1852 the ASCE have served civil engineers worldwide and also the construction industry, after all of this still they do not have construction safety committee. Civil engineers from all over the world take guidance about every project from ASCE. Safety is very crucialpart of the civil engineering.

Jimmie Hinze, M.ASCE, Matthew Hallowell, A.M.ASCE and Kevin Baud [9] According to them after the Occupational Safety and Health Act 1970 which was approved by congress, the improvement has been experienced in the construction industry related to the safety . In the last few years some improvement has been made with due respect to safety directive in the construction industry. But there is still a need to formulate better tactics for safety during construction projects.

How Sing Siia, Tom Ruxtona, JinWangb [8] have used Fuzzy logic to develop a safety model, by using the IFTHEN rule of human evidence and questioning without using precise quantitative analyses that can model the quantitative aspect. The research has been done to target the development of linguistic variables.

Adam S. Markowskia, M. Sam Mannanb, AgataBigoszewskaa[1] determine the functions of fuzzy set\& explores the application of fuzzy sets concept in terms of basic tools used in practicing safety analysis such as fault and event tree methods which can further be used in the "bow-tie" approach for accident scenario risk assessment. In the traditional fault and event tree analyses, the input variables are taken as exact values and the exact outcome data are received by asuitable mathematical approach. In the fuzzy method, all variables are switched by fuzzy numbers in the process of fuzzification and successively using fuzzy arithmetic, fuzzy probability of the top event for fault tree, and fuzzy outcome probabilities for event tree are calculated. A single value for each of the outcome event result can be obtained with the use of one of the defuzzification methods. A characteristic case study consisting of a fault tree for rupture of the iso-butane storage tank and the event tree for its consequences is achieved and anassessmentamongst the traditional approach and fuzzy method is prepared.

D. Singh and Robert L. K. Tiong [6] have explained the best process for the selection of the contractor according to the need of the project so that the best construction can be achieved in the worth amount of the money.

\section{METHODOLOGY}

Figure-1 showsa flow diagram of developed methodology.

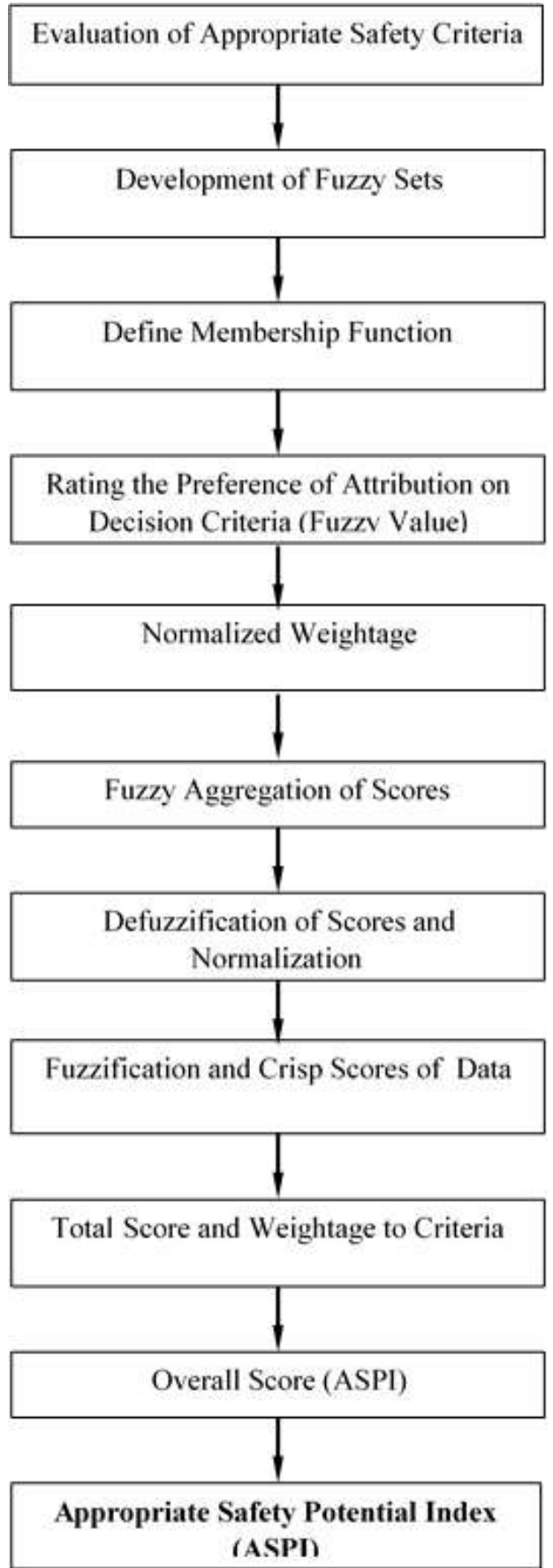

Fig-1: A flow diagram of methodology

\subsection{Fuzzy Set \& Fuzzy Logic}

A fuzzy set can be defined mathematically to every individual which has a degree or grade of membership in the particular set of fuzzy. Which represents the degree to which individual is similar with the concept explained by the fuzzy set. Thus, individual can belong greater or lesser degree in the fuzzy set. Membership grades arerepresented by real number ranging close between the As, fuzzy logic deals with form of values logic where truth values of variables can be any real number range between 0 and 1 , it is a multi- 
valued type of the logic. By the human being reasoning, information and also common sense questioning the results are close to appropriate results which derives in the Fuzzy logic. (Klir and Yuan, 2003)

\subsection{Linguistic Variable}

The fuzzy number plays an important role to elaborate quantitative fuzzy variables. The fuzzy numbers represent linguistic values, such as- very good, good, fair and etc.

For our study, the linguistic terms used are- very important, important, average, least important, and very least important. The table below showing the linguistic terms and fuzzy numbers used. Fig. 2 shows linguistic terms which are presented by graph of fuzzy numbers:

Table-1: Linguistic Terms and Fuzzy Numbers

\begin{tabular}{|l|l|}
\hline LINGUISTIC TERMS & FUZZY NUMBER \\
\hline VI (Very Important) & $(0.777,0.888,1.000,1.000)$ \\
\hline I (Important) & $(0.555,0.666,0.777,0.888)$ \\
\hline A (Average) & $(0.333,0.444,0.555,0.666)$ \\
\hline LI (Least Important) & $(0.111,0.222,0.333,0.444)$ \\
\hline VLI (Very Least Important) & $(0.000,0.000,0.111,0.222)$ \\
\hline
\end{tabular}

$\mu(\mathbf{x})$

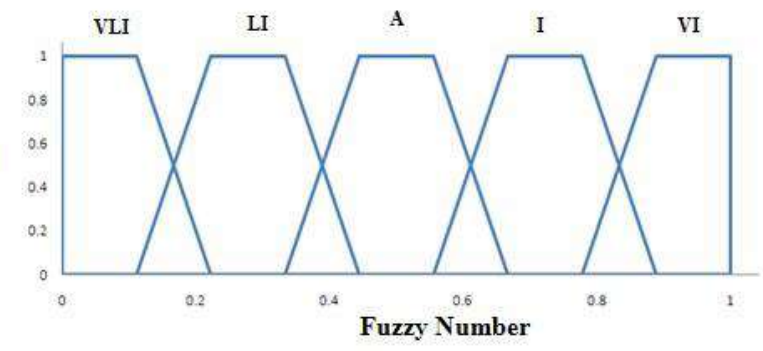

Fig-2: Fuzzy Sets

Expert's opinion from the field of civil engineering are taken from professionals and academicians, for sub criteria for Contractor's need, Safety details, PPE, worker safety, traffic safety, equipment

Certificationand other safety.

\subsection{Average Fuzzy Number (AFN)}

The further average fuzzy number can be calculated by the linguistic terms given by the experts.

The terms that are allocated by experts for every sub criterion of the Contractor's need, Safety details, PPE, worker safety, traffic safety, equipment certification, and other safety can be transformed into fuzzy numbers. Then AFN will be equated by the following calculations.

$\mathrm{A}_{\mathrm{ij}}^{p}=(1 / E) \cdot\left(\mathrm{a}_{\mathrm{i} 1}^{p}+\mathrm{a}_{\mathrm{i} 2}^{p}+\ldots+\mathrm{a}_{\mathrm{iE}}^{p}\right)$ for $\mathrm{i}=1,2, . ., \mathrm{n} \& \mathrm{j}=1,2, \ldots, \mathrm{E}$

Where,

$A_{\mathrm{ij}}^{p}=$ Fuzzy number assigned to a sub criterion,
$\mathrm{E}=$ Number of experts \&

$\mathrm{n}=$ Number of fuzzy numbers.

\subsection{Defuzzification \& Normalized Weight}

It is a calculation that creates a non-fuzzy or crisp value which sufficiently represents the level of fulfilment of the combined fuzzy number. In our study, trapezoidal fuzzy set are considered. A significance of sub criterion was thoughtof as range value but not with a certain value. So, only trapezoidal fuzzy sets were considered. Let a Trapezoidal fuzzy number be limited to $\mathrm{x} 1, \mathrm{x} 2, \mathrm{x} 3$ and $\mathrm{x} 4$ as shown in the Figure then its de-fuzzified value (crisp score) 'e'. For the criterion can be obtained by using the following (Kaufman and Gupta, 1991).

$e=(x 1+x 2+x 3+x 4) / 4$

\subsection{Fuzz Decision Matrix}

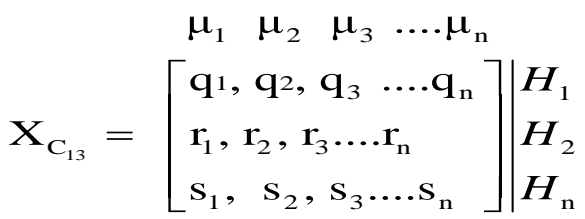

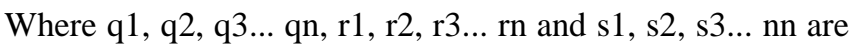
fuzzy values of Safety goggles for Project 1, 2 and 3 respectively

\subsection{The Crisp Scores}

Crisp scores of sub criterion for every project can be obtained by using following equations:

$$
\begin{array}{r}
\mathrm{H}_{1}=\left(\mathrm{lq}_{1}+\mathrm{q}_{2}+\mathrm{q}_{3}+\ldots+\mathrm{q}_{\mathrm{n}}\right) / \mathrm{n} \\
\mathrm{H}_{2}=\left(\mathrm{r}_{1}+\mathrm{r}_{2}+\mathrm{r}_{3}+\ldots+\mathrm{r}_{\mathrm{n}}\right) / \mathrm{n} \\
\mathrm{H}_{\mathrm{n}}=\left(\mathrm{s}_{1}+\mathrm{s}_{2}+\mathrm{s}_{3}+\ldots+\mathrm{s}_{\mathrm{n}}\right) / \mathrm{n}
\end{array}
$$

\subsection{Total Score}

As per the simple additive method which was developed by Hwang and Yoon, 1981, total score for the different schemes can be calculated using equation as shown below, with usual notations

$$
\mathrm{TS}_{\mathrm{ci}}=\sum\left[\mathrm{X}_{\mathrm{cp}} \cdot \mathrm{W}\left(\mathrm{C}_{\mathrm{cp}}\right)\right] \text { for } \mathrm{p}=1,2,3,4, \ldots \mathrm{n}
$$

Where,

$\mathrm{TS}_{\mathrm{ci}}=$ total score of the highway project against the criterion $\mathrm{c}$

$\mathrm{X}_{\mathrm{cp}}=$ crisp score of the highway project data against Sub-criterion $\mathrm{p}$ of the criterion $\mathrm{c}$

$\mathrm{W}\left(\mathrm{C}_{\mathrm{cp}}\right)$ = weight (importance value) of sub criterion $\mathrm{p}$ of the criterion $\mathrm{c}$ 
Now, safety potential importance weight $\left[\mathrm{W}\left(\mathrm{C}_{\mathrm{ci}}\right)\right]$ of these criterion c for project 1 can be calculated as,

$\mathrm{W}\left(\mathrm{C}_{\mathrm{ci}}\right)=\mathrm{TS}_{\mathrm{ci}} / \sum \mathrm{TS}_{\mathrm{ci}}$

\subsection{Overall Score}

As per the additive weighing method which was developed by Hwang and Yoon, 198, overall score for the different projects can be calculated using the following equation, with usual notations

$\mathrm{OS}=\sum\left[\mathrm{TS}_{\mathrm{ci}} \cdot \mathrm{W}\left(\mathrm{C}_{\mathrm{ci}}\right)\right]$ for $\mathrm{i}=1,2, \ldots \mathrm{n}$

\section{ILLUSTRATIVE EXAMPLE}

For this study the data of safety were collected from 3 highway projects which are in the vicinity of PCMC Pune, Maharashtra, India For the selection of appropriate safety four criteria were considered like PPE, worker safety, traffic safety and equipment certification.

The following sub criteria of defined criteria are considered for the study:

Personal Protective Equipment (PPE): Helmet, Hard hats, Safety goggles, Gloves, High Visibility Clothing, Safety Boots, Earplugs, Mask and Toe Guards.

Worker Safety: Safety Training, Temporary Traffic Control, Worker Safety for Highway Construction Standards, Workers Visibility, Facts and Statistics, National Work Zone Awareness and Additional Resources.

Traffic Safety: Distance of Sign Boards, Visibility of Labour, Traffic Control, Diversion of Traffic, Signals and Barricades.

Equipment Certification: Appropriate License for JCB Operator, Certification of Respective Equipment, Maintenance schedule of Equipment and Equipment Safety.

The table-2 shows experts opinion by professionals for sub criteria of PPE.

Table-2: Expert Opinion (Professional)

\begin{tabular}{|l|l|l|l|l|l|}
\hline SUB CRITERIA & SP & SP & SP & SP & SP \\
& 1 & 2 & 3 & 4 & 5 \\
\hline Helmet & VI & VI & VI & VI & VI \\
\hline Hard hats & I & VI & I & I & VI \\
\hline Safety goggles & A & VI & I & I & VI \\
\hline Gloves & A & VI & I & I & VI \\
\hline $\begin{array}{l}\text { High visibility } \\
\text { clothing }\end{array}$ & A & VI & VI & VI & VI \\
\hline Safety boots & I & VI & VI & VI & VI \\
\hline Earplugs & A & I & I & I & I \\
\hline Mask & A & I & I & A & I \\
\hline Toe guard & LI & I & I & I & I \\
\hline
\end{tabular}

$\mathrm{SP}=$ Safety Professional Expets

\section{RESULTS AND DISCUSSION}

Evaluation of Appropriate Safety Potential Index (ASPI) The fuzzy Multi Criteria Decision Making method was used for the calculation of SPI. The normalized weight for each sub criterion of PPE,Workers safety, Traffic Safety and Equipment Certification was calculated.

Then, Total score was calculated for criteria by using equation (v). Similarly, Total score for other criteria was calculated. Table-3 shows Total score.

Table-3: Total score (Academician and Professional)

\begin{tabular}{|l|l|l|l|l|}
\hline & Criteria & $\begin{array}{l}\text { Project } \\
\mathrm{A}\end{array}$ & $\begin{array}{l}\text { Project } \\
\mathrm{B}\end{array}$ & $\begin{array}{l}\text { Project } \\
\mathrm{C}\end{array}$ \\
\hline Academicias & \multirow{2}{*}{ PPE } & 1 & 0.891 & 0.901 \\
\cline { 3 - 5 } & & 0.666 & 0.734 & 0.693 \\
\hline Professionals & & & & \\
\hline Academicias & \multirow{2}{*}{$\begin{array}{l}\text { Worker } \\
\text { safety }\end{array}$} & 0.645 & 0.748 & 0.652 \\
\cline { 1 - 4 } & & 0.671 & 0.742 & 0.661 \\
\hline Professionals & & & & \\
\hline Academicias & \multirow{2}{*}{$\begin{array}{l}\text { Traffic } \\
\text { safety }\end{array}$} & 0.838 & 0.754 & 0.689 \\
\cline { 1 - 4 } & & 0.751 & 0.668 & 0.684 \\
\hline Professionals & & & & \\
\hline Academicias & \multirow{2}{*}{$\begin{array}{l}\text { Equipmnt } \\
\text { Professionals }\end{array}$} & 0.747 & 0.751 & 0.871 \\
\cline { 3 - 5 } & & 0.991 & 0.832 & 0.912 \\
\hline
\end{tabular}

Then, Overall score was calculated using equation (vii) Table-4 shows overall score or SPI of Academicians.

Table-4: Overall Score or Safety Potential Index (Academicians)

\begin{tabular}{|l|l|l|}
\hline Project & Overall Score & Remark \\
\hline 1 & 0.801 & Not Safe \\
\hline 2 & 0.796 & Least Safe \\
\hline 3 & 0.792 & Least Safe \\
\hline
\end{tabular}

Table- 5 shows overall score or SPI of Professionals

Table-5: Overall Score or Safety Potential Index (Professionals)

\begin{tabular}{|l|l|l|}
\hline Project & Overall Score & Remark \\
\hline 1 & 0.782 & Least Safe \\
\hline 2 & 0.734 & Least Safe \\
\hline 3 & 0.750 & Least Safe \\
\hline
\end{tabular}

On the basis of values of Appropriate Safety Potential Index (SPI) client can see appropriateness of projects with the help of SPI scale

Table-6: Safety Potential Scale

\begin{tabular}{|l|l|l|}
\hline Sr. No. & Scale & Linguistic Term \\
\hline 1. & $0.00-0.20$ & Highly Safe \\
\hline 2. & $0.21-0.40$ & Safe \\
\hline 3. & $0.41-0.60$ & Moderately Safe \\
\hline 4. & $0.61-0.80$ & Least Safe \\
\hline 5. & $0.81-1.00$ & Not Safe \\
\hline
\end{tabular}




\section{CONCLUSION}

Using the MCDM method the SPI that is Safety Potential Index model have been developed to decide Appropriate Safety Management in Highway Projects, Residential Buildings and Roads.

The following are the conclusions on the basis of the analysis:

i) For the selection of safety by the Fuzzy logic is found to be more applicable comparing to the crisp approach.

ii) The index value fluctuate slightly, when we relate the linguistic values of Academicians and Professionals.

\section{REFERENCES}

[1] Adam S. Markowskia, M. Sam Mannanb, AgataBigoszewskaa. (2014). "Fuzzy logic for process safety analysis". Journal of loss prevention in process industries. November 2009, Vol. 22(6):695-702.

[2] Zadeh [1965] "Fuzzy sets" Information and Control, 8: 338-353.

[3] C.E.Jackson Jr, (1993), "Discussion of ASCE should have a Construction Safety Committee". J. Prof. Issues Eng. Educ. Pract., ASCE Journal, 118(1): 5659.

[4] Chien-Chang Chou, "Integrated Short- Term and Long-Term MCDM Model for solving location selection problem". No. 11, November 1, 2009, @ ASCE, Vol. 135: 137-142.

[5] C.E.Jackson Jr, (1993), "Discussion of ASCE should have a Construction Safety Committee". J. Prof. Issues Eng. Educ. Pract., ASCE Journal, 118(1): 5659.

[6] D. Singh and Robert L. K. Tiong, "A Fuzzy Decision Framework for Contractor Selection" Journal of Construction Engineering and Management, 1,62 January, 2005, ASCE

[7] Frank Gross, Ph.D and Paul P. Jovanis, Ph.D [2007] "Estimation of the Safety Effectiveness of Lane and ShoulderWidth: Case-Control Approach"J. Transp. Eng.,133(6)

[8] How Sing Siia, Tom Ruxtona, JinWangb (2001) “A Fuzzy logic based approach to qualitative safety modelling for marine system", Reliability Engg. \& System Safety, July 2001, Vol. 73(1): 19-34.

[9] Jimmie Hinze, M.ASCE, Matthew Hallowell, A.M.ASCE and Kevin Baud(2013) "ConstructionSafety Best Practices and Relationships to Safety Performance" J. Constr. Eng. ManageVolume 139, sIssue 10

[10] Jimmie Hinze [1988] "Safety on Large Building Construction Projects" J. Constr. Eng. Manage, 114(2): 286-293

[11] Matthew R. Hallowell and John A. Gambatese [2009] “Construction Safety Risk Mitigation"J. Constr. Eng. Manage. 135(12)

[12] M. Medineckiene, E.K. Zavadskas, Z. Turskis, (2011). "Dwelling selection by applying Fuzzy game theory", Archives of Civil and Mechanical Engg., 2011, Vol. 11(2): 681-697.
[13] Richard J. Coble and Robert L. Blatter Jr. [1999] "Concerns with Safety in Design/Build Process" J. Archit. Eng 5(2): 44-48

[14] Saaty, T. L. (1977). "A scaling method for priorities in hierarchical structures." Journal of Mathematical Psychology, 15, 234-281.

[15] Zongzhi Li, Konstantinos Kepaptsoglou, Yongdoo Lee, Harshingar Patel, Yi Liu, and Han Gyol Kim (2013),"Safety Effects of Shoulder Paving for Rural and Urban Interstate, Multilane and Two-way Highways", Journal of transportation engineering (C) ASCE / October 2013: 1012-1014 